\title{
A NEW MODIFIED FE(III)-SELECTIVE SOLID MEMBRANE ELECTRODE
}

\author{
Ece Düzgün, Mustafa Taştekin", Orhan Atakol \\ Department of Chemistry, Faculty of Science, \\ Ankara University, 06100 Ankara, Turkey
}

\begin{abstract}
In this study, a Fe(III)-selective solid state membrane electrode based on $\mathrm{AgFeS}_{2}-\mathrm{FeS}_{\mathrm{x}}(\mathrm{x}=2-3)$ mixture was developed. This electrode exhibited a linear Nernstian response over the range $10^{-2}-10^{-5} \mathrm{M}$ of iron(III) with a slope of $18.7 \pm 0.8 \mathrm{mV}$ per $\mathrm{p}[\mathrm{Fe}]$. The effects of the $\mathrm{pH}$ and the lifetime of the electrode were investigated. The selectivity coefficients for some common cations were calculated by the mixed-solution method. The preparation procedure of the electrode is easy and inexpensive. Moreover, the proposed electrode was applied for the determination of iron in standard reference materials.
\end{abstract}

Keywords: Iron(III), Sulfur based membrane, Ion-selective electrode, Potentiometry

\section{INTRODUCTION}

In recent decades, many intensive studies about ion-selective electrodes (ISE) have been reported. In spite of increasing studies dealing with ISE, the reports about iron-selective electrodes are relatively scarce /1-6/. In these studies the different types of electrodes were prepared such as poly(vinyl chloride) membrane electrodes, coated wire electrodes and solid-state

"Corresponding author. Tel.: +90-312-2126720/1281; Fax: +90-312-2232395

E-mail address: tastekin@science.ankara.edu.tr 
electrodes were used for the determination of iron.

As is known, membranes which sensitive towards metal ions can be made by using $\mathrm{Ag}_{2} \mathrm{~S}-\mathrm{MS}(\mathrm{M}=$ metal) mixture. Silver ion must be present in these membranes to conduct electricity because divalent ions are immobile in crystals. On the other hand silver ions are sufficiently mobile to conduct electricity through the solid medium. The sensitivity of these types of membranes towards $\mathrm{Fe}$ (III) ions was reported for the first time by Fung and Fung in $1977 / 6 /$. In that study a copper-selective electrode with a membrane of mixed $\mathrm{Ag}_{2} \mathrm{~S}-\mathrm{CuS}$ is used to measure $\mathrm{Fe}$ (III) ions in aqueous solutions. In order to increase the sensitivity of the membrane towards Fe(III) ions $\mathrm{AgFeS}_{2}$ was used instead of CuS in our study.

\section{EXPERIMENTAL}

Potential measurements were carried out with a Jenway 3040 ion Analyzer $\mathrm{pH}$-ionmeter. The reported potential values are given against a $\mathrm{Ag} / \mathrm{AgCl}$ reference electrode. Measurements were made with the electrodes immersed to a depth of $1.5 \mathrm{~cm}$ in a sample solution being stirred by a magnetic stirrer. All of the experimental works were carried out at $20 \pm 1^{\circ} \mathrm{C}$ and $\mathrm{pH}$ values were determined using a combined glass-pH electrode (Ingold $\mathrm{U} 402-\mathrm{S} 7 / 120$ 402.3311)

All of the chemicals were analytical grade and used without further purification. All of the solutions were prepared using deionized water. The $1 \mathrm{M}$ stock $\mathrm{Fe}(\mathrm{III})$ solution was prepared from ferric nitrate and adjusted according to the Zimmermann Reinhardt method /8/. Solutions of $1 \times 10^{-1}$ to $1 \times 10^{-6} \mathrm{M}$ were freshly diluted from the I $\mathrm{M}$ stock solution of iron(III).

The proposed electrode was applied to determine iron in a standard ion sample. Standard reference material (Schwefelkies IX: $46.47 \% \mathrm{~S}, 40.82 \% \mathrm{Fe}$, $0.21 \% \mathrm{Cu}, 0.82 \% \mathrm{~Pb}, 0.43 \% \mathrm{Zn}$ and $0.52 \% \mathrm{As}$ ) was obtained from $\mathrm{Dr}$. Hoefner's Subztanz Firm. A suitable amount was taken from the standard reference material and was dissolved by using nitric acid. Then it was diluted to a certain volume.

The membrane was prepared in a similar method given for $\mathrm{AgFeS}_{2}$ preparation in literature $17 / .12 .5 \mathrm{~g}$ of anhydrous $\mathrm{K}_{2} \mathrm{CO}_{3}, 7.65 \mathrm{~g}$ of $\mathrm{AgNO}_{3}$, $2.50 \mathrm{~g}$ of iron powder and an excessive amount of elemental sulfur were slowly heated from $60^{\circ} \mathrm{C}$ to $550^{\circ} \mathrm{C}$ in a $60 \times 200 \mathrm{~mm}$ pyrex cylindrical vessel 
under $\mathrm{H}_{2} \mathrm{~S}+\mathrm{N}_{2}$ atmosphere for 4 hours and then cooled to room temperature. The mixture was then taken out, the heterogeneous parts were cleaned off and the remaining black homogenous part was crushed into a powder. The excessive sulfur was separated by washing with $10 \mathrm{~mL} \mathrm{CS}_{2}$ at $50^{\circ} \mathrm{C}$ for $6-7$ times. Then it was washed with ethyl alcohol and dried at $80^{\circ} \mathrm{C}$. The dry powder was put in a press and subjected to $800 \mathrm{mPa}$ pressure for 5 minutes. The discs were then removed and one side was polished to prepare a membrane. The copper wire was attached the unpolished side of membrane for electrical contact. The disc was then mounted onto a glass tube $1 \mathrm{~cm}$ diameter. The electrode was instantly ready for use.

The following electrochemical cell was established with the prepared iron(III)-selective electrode:

$\mathrm{Ag}, \mathrm{AgCl} / \mathrm{KCl}$ (sat.) / Sample solution / Membrane / Cu wire

Potassium, silver, iron and sulfur in the prepared membrane were analyzed by atomic absorption spectrometric method and classical analytical methods $/ 8$. The results have been given as $\% \mathrm{Ag} 6.82, \% \mathrm{Fe} 34.66, \% \mathrm{~S}$ 58.40. Potassium was seen to trace. According to these results the membrane is thought to be of $\mathrm{AgFeS}_{2}-\mathrm{FeS}_{\mathrm{x}}(\mathrm{x}=2-3)$ structure.

\section{RESULTS AND DISCUSSION}

The potentiometric response of the prepared iron(III)-selective solid state membrane electrode was investigated against the iron(III) ion concentration. For this purpose, appropriate aliquots of stock solution of iron(III) were introduced to the cell and the corresponding potentials were determined. For a fixed ionic strength, all of the measurements were made in a $0.5 \mathrm{M}$ sodium perchlorate because of its well-known week tendency of forming a complex with iron(III).

The $\mathrm{pH}$ values of these solutions were adjusted to 2.3 using $\mathrm{HClO}_{4}$ and $\mathrm{NaOH}$. The potential readings were plotted against $-\log$ of iron(III) concentration. Over the concentration range $10^{-2}-10^{.5} \mathrm{~mol} / \mathrm{L}$ of iron(III) in the calibration solution, the electrode potential response was linear with the concentration of iron(III), (Fig 1). The calibration curve slope was $18.7 \pm 0.8$ $\mathrm{mV} / \mathrm{p}[\mathrm{Fe}]$ and the detection limit, calculated as recommended by the IUPAC, was $5.1 \times 10^{-6} \mathrm{M} / 9 /$. 


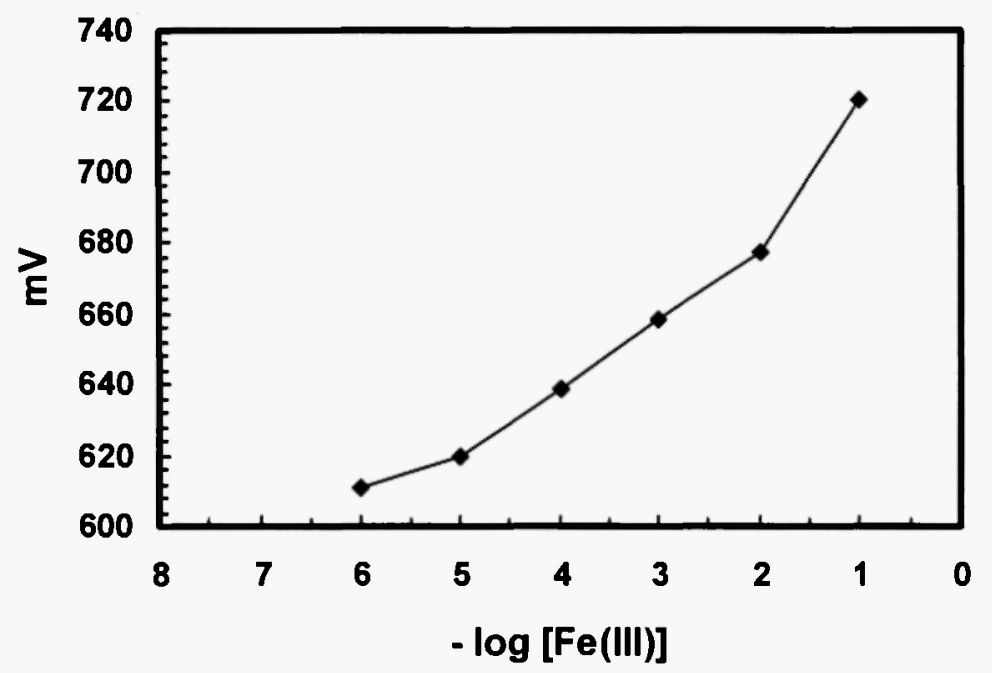

Fig. 1: The calibration curve of the proposed iron(III)-selective electrode at pH 2.3

The effect of the $\mathrm{pH}$ on the prepared electrode potential response was studied. The $\mathrm{pH}$ of the solution was changed between 1.5 and 3.0 by adding suitable volumes of perchloric acid to $1.0 \times 10^{-3} \mathrm{M}$ iron(III) solution and measure potentiometrically with the combined glass-pH electrode. When these $\mathrm{pH}$ values were plotted against $\mathrm{pH}$, it was observed that the potential remains constant at the $\mathrm{pH}$ range $2.2-2.4$, (Fig 2). At $\mathrm{pHs}$ higher than 2.4, iron(III) ions started to hydrolyze by forming iron(III) hydroxide from the sample solution. At pHs lower than 2.2, the potential values decrease as $\mathrm{pH}$ values decrease because of the interference effects of the hydrogen ions in the test solutions. Therefore, the $\mathrm{pH}$ values of the solutions were kept at 2.3 .

The lifetime of the electrode was determined by recording its potentials at the optimum $\mathrm{pH}$ value and plotting its calibration curve each day for a period of a year. It was observed that there was no significant change in the slope of the electrode on the following day. At the end of a month, the slope of the electrode was found to be $17.9 \mathrm{mV}$; however it increased to its first value after conditioning the electrode in $10^{-3} \mathrm{M} \mathrm{Fe}\left(\mathrm{NO}_{3}\right)_{3}$ solution for 30 minutes. After one year the electrode was still working and its slope was seen to remain stable by conditioning. According to our observations, we can claim that the lifetime of the electrode is quite long. 


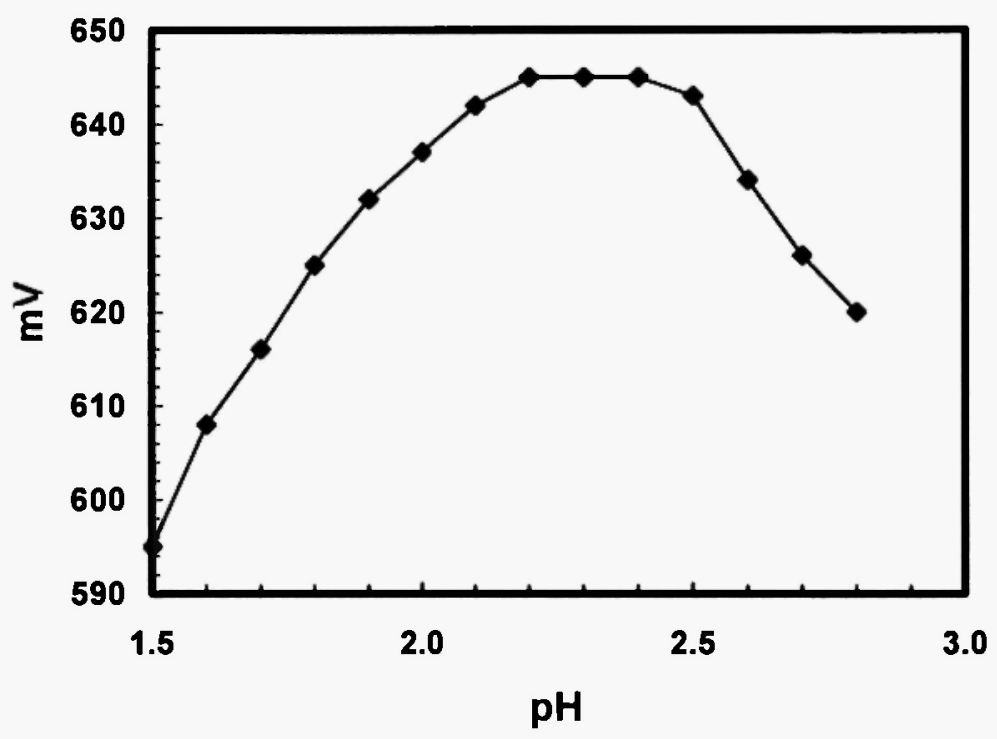

Fig. 2: The determination of optimum working $\mathrm{pH}$ range of the proposed iron(III)-selective electrode

The selectivity coefficients $\left(\mathrm{K}_{\mathrm{Fe}} \mathrm{X}\right)$ of the iron(III)-selective electrode were calculated by the mixed solution method /10, 11/ from potential measurements of solutions prepared with a fixed iron(III) concentration and varying concentration of the interference ion. In this work, interference studies were made for $\mathrm{Cr}$ (III), $\mathrm{Mn}$ (II), $\mathrm{Fe}(\mathrm{II}), \mathrm{Co}(\mathrm{II}), \mathrm{Ni}(\mathrm{II}), \mathrm{Cu}(\mathrm{II}), \mathrm{Zn}$ (II), $\mathrm{Ag}$ (I) and $\mathrm{Pb}$ (II) ions. As can be seen from Table 1, the most interfering cations to the electrode are $\mathrm{Ag}(\mathrm{I}), \mathrm{Cu}$ (II) and $\mathrm{Mn}$ (II). This is the case for most of the studies discussed in the literature $15,13 /$. However, the selectivity coeficients of the iron(III)-selective electrode against the other cations investigated are in good compliance with the literature data.

These results show that the iron(III)-selective electrode which we prepared is superior to most of the iron(III)-selective electrodes mentioned in the literature as regards to the detection limit and the life time /4-6/.

The proposed electrode was applied to determine iron in a standard reference material. For this purpose, the solutions prepared from standard reference material were potentiometrically titrated with EDTA by using the proposed iron(III)-selective electrode as an indicator electrode (Fig 3). The 
obtained results were compared with those obtained by the ZimmermannReinhardt method /8/ and the results are given in Table 2. As can be seen from Table 2 , it is obvious that the results of iron determination in a standard reference material using these two methods are compatible within the $95 \%$ confidence level.

\section{Table 1}

The potentiometric selectivity coefficients of the proposed $\mathrm{Fe}(\mathrm{III})$-selective electrode.

\begin{tabular}{lr}
\hline $\mathbf{X}$ & $\mathbf{K}_{\mathrm{Fe}, \mathbf{X}}$ \\
\hline $\mathrm{Ag}^{+}$ & $12,6 \pm 0,401$ \\
$\mathrm{Co}^{2+}$ & $0,41 \pm 0,030$ \\
$\mathrm{~Pb}^{2+}$ & $0,43 \pm 0,062$ \\
$\mathrm{Zn}^{2+}$ & $0,46 \pm 0,087$ \\
$\mathrm{Ni}^{2+}$ & $0,47 \pm 0,082$ \\
$\mathrm{Cu}^{2+}$ & $5,97 \pm 0,303$ \\
$\mathrm{Fe}^{2+}$ & $0,40 \pm 0,053$ \\
$\mathrm{Mn}^{2+}$ & $1,05 \pm 0,138$ \\
$\mathrm{Cr}^{3+}$ & $0,0093 \pm 4,8 \times 10^{-4}$ \\
\hline
\end{tabular}

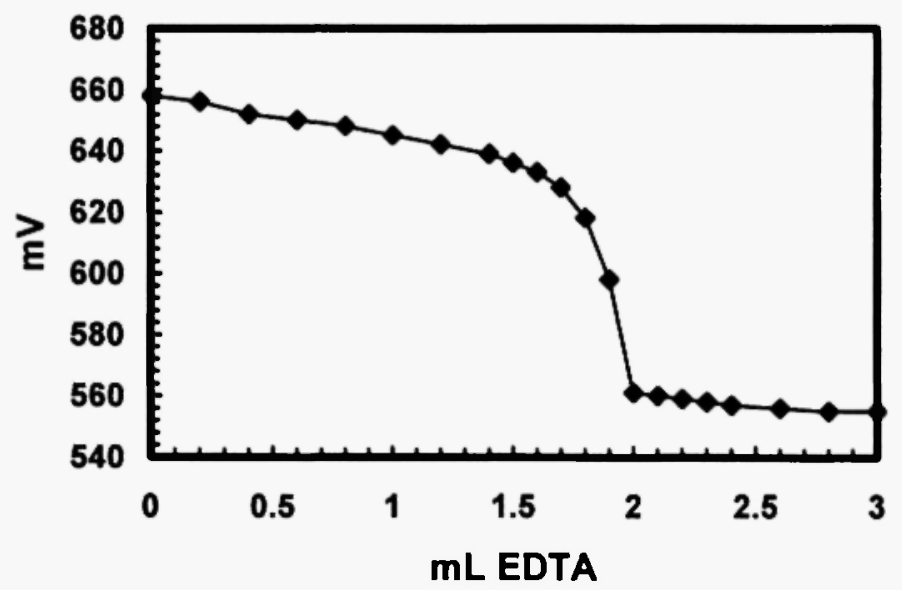

Fig. 3: The potentiometric titration curve of the solution of the standard reference material with EDTA obtained using the proposed iron(III)selective electrode. 


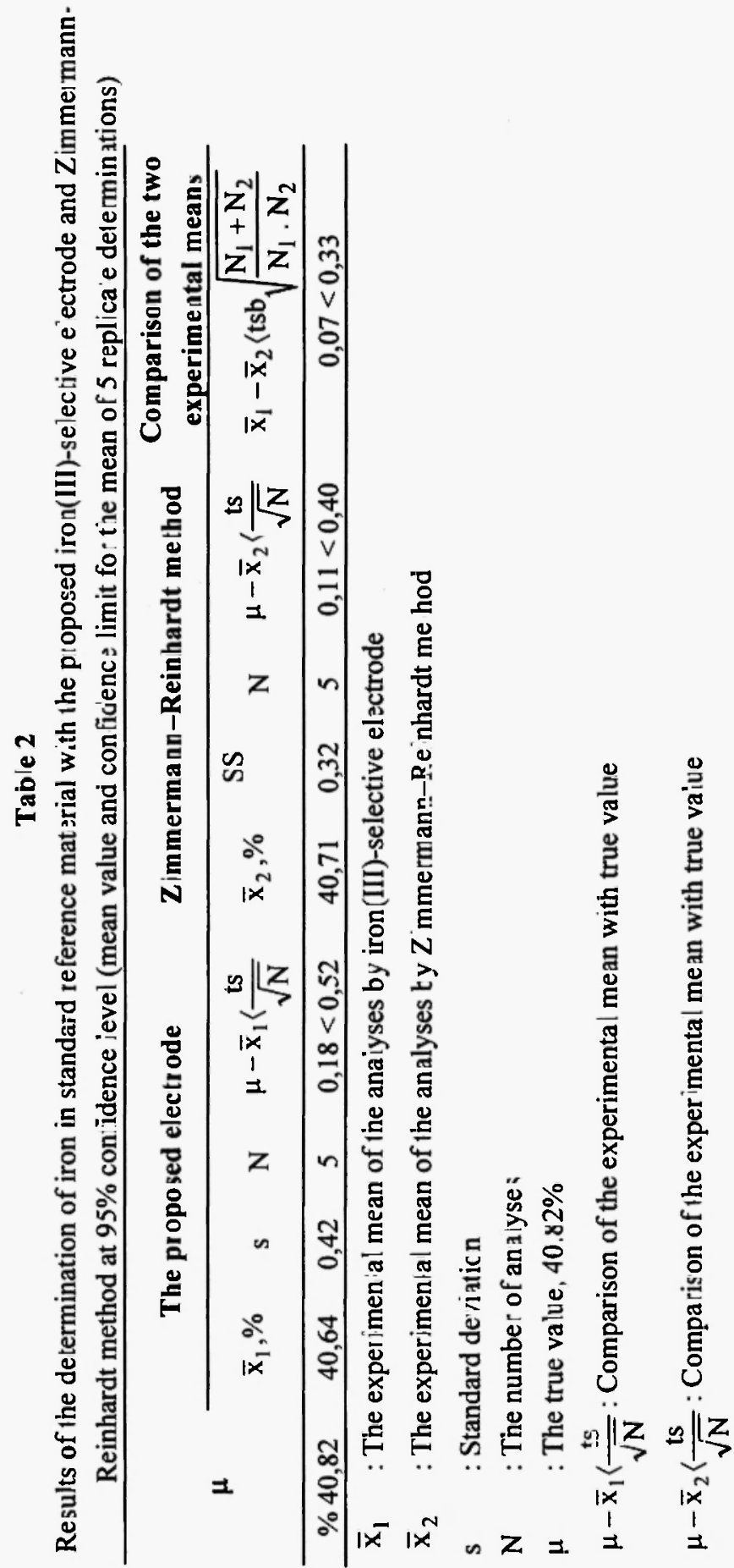




\section{REFERENCES}

1. P. Bühlmann, E. Pretsch and E. Bakker, Chem. kev. 98 (1998) 1593.

2. E. Bakker, P. Bühlmann and E. Pretsch, Chem. Rev. 97 (1997) 3083.

3. S.M. Hassan and S.A.M Marzouk, Talanta. 41 (1984) 891.

4. M.B. Saleh, Analyst $125(2000) 179$.

5. Y.S. Fung and K.W. Fung, Anal. Chem. 49(3) (1977) 497.

6. R.W. Cottrall and P. Chin-Poh, Anal. Chem. 347 (1975) 93.

7, G. Brauer, Handbuch der Praperativen Anorganischen Chemic Ferdnand Enke Verlag Stuttgart, 1954.

8. D.A. Skoog, D.M. West, F.J. Holler, Analytical Chemistry, Saunders College Publishing, Seventh Edition, 1996.

9. IUPAC, Pure Appl. Chem. 48 (1976) 27.

10. E. Pungor, K. Toth and P. Hrabeczy, Pure Appl. Chem. 51 (1979) 1913.

11. K. Srinivasan, G.A. Rechnitz, Anal. Chem. 41 (1969) 1203.

12. F.P.K. Toth, E. Pungor, M. Farkasjahnke, H. Ebel, M.F. Ebel, Analytica Chimica Acta 180 (1986) 313.

13. A. Hulanicki and T. Krawcynski vel Krawcyk, Talanta 44(4) (1987) 856. 